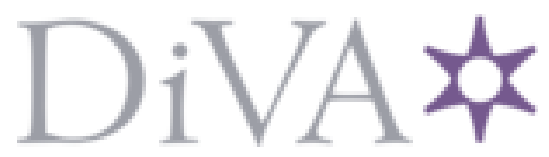

http://www.diva-portal.org

This is the published version of a paper published in International psychogeriatrics.

Citation for the original published paper (version of record):

Wallin, K., Boström, G., Kivipelto, M., Gustafson, Y. (2013)

Risk factors for incident dementia in the very old.

International psychogeriatrics, 25(7): 1135-1143

http://dx.doi.org/10.1017/S1041610213000409

Access to the published version may require subscription.

N.B. When citing this work, cite the original published paper.

Permanent link to this version:

http://urn.kb.se/resolve?urn=urn:nbn:se:umu:diva-79261 


\title{
Risk factors for incident dementia in the very old
}

\author{
Karin Wallin, 1,2,3 Gustaf Boström, ${ }^{3}$ Miia Kivipelto ${ }^{1,2,4,5}$ and Yngve Gustafson ${ }^{3}$ \\ ${ }^{1}$ Aging Research Center (ARC), Karolinska Institutet and Stockholm University, Stockholm, Sweden \\ ${ }^{2}$ Karolinska Institutet Alzheimer Disease Research Center (KI-ADRC), Karolinska Institutet, Stockholm, Sweden \\ ${ }^{3}$ Department of Community Medicine and Rehabilitation, Geriatric Medicine, Umeå University, Umeå, Sweden \\ ${ }^{4}$ Department of Chronic Disease Prevention, National Institute for Health and Welfare, Helsinki, Finland \\ ${ }^{5}$ Department of Neurology, Kuopio University Hospital and University of Eastern Finland, Kuopio, Finland
}

\section{ABSTRACT}

Background: Several risk factors for dementia, Alzheimer's disease, and cognitive impairment have been established; however, knowledge about risk factors in the very old population ( $\geq 85$ years) is limited. This study describes the association of several baseline factors with dementia in participants aged $\geq 85$ years, and investigates factors associated with a higher risk of incident dementia over five years.

Methods: The participants in this population-based cohort study were aged 85,90 , and $\geq 95$ years at baseline (2000-2002). Data were collected during home visits for interviews and testing, from a review of medical records, and/or interviewing the caregiver or next of kin. After five years 212 participants could be followed up concerning incident dementia. Multivariate logistic regression was used.

Results: At baseline, 100/353 (28\%) of participants had a dementia diagnosis. Over five years, 71/212 (33.5\%) participants developed dementia. Few participants with dementia at baseline remained alive after five years $(12 \%)$. Depression at the baseline and follow-up time were associated with a higher risk of dementia, odds ratio (OR) $(95 \% \mathrm{CI}$, p-value) $2.91(1.37-6.16,0.005)$ and $1.61(1.26-2.05,<0.001)$ respectively. More social contact and a higher Mini-Mental State Examination score at baseline were associated with lower risk of incident dementia, OR (95\% CI, p-value) $0.87(0.78-0.97,0.009)$ and $0.83(0.74-0.93,0.001)$ respectively.

Conclusions: Prevalence and incidence of dementia are high in very old people and dementia appears to be a fatal disorder. Depression is associated with higher risk of incident dementia over five years whereas more frequent social contacts and a higher MMSE score are associated with lower risk.

Key words: aged, 80 and over, longitudinal, population-based, depression, social isolation, prevalence, incidence

\section{Introduction}

The size of the older population is increasing worldwide, and those 80 years and older comprise the fastest growing group (United Nations, Population Division, 2010). The prevalence of dementia increases with age, from $1.5 \%$ in $60-69-$ year-old individuals to $40 \%$ in nonagenarians (Qiu et al., 2007). An age-specific increase in prevalence of dementia in the very old has been reported (Mathillas et al., 2011). Established risk factors for the development of dementia, Alzheimer's disease (AD), and cognitive impairment (CI) are old age, low level of education, and heredity (Qiu et al., 2007). There is increasing evidence pointing to additional risk factors from midlife to late-life, such as hypertension, high Body Mass Index (BMI), dia-

Correspondence should be addressed to: Karin Wallin, Aging Research Center, Karolinska Institutet and Stockholm University, Gävlegatan 16, SE-11330 Stockholm, Sweden. Phone: +46-730-52-48-94; Fax: +46-8-690-59-54. Email: Karin.Wallin@ki.se. Received 17 Oct 2012; revision requested 30 Nov 2012; revised version received 3 Mar 2013; accepted 4 Mar 2013. First published online 11 April 2013 betes, cardiovascular and cerebrovascular diseases, and smoking (Qiu et al., 2007). Psychosocial factors are important and lack of social networks, few leisure activities, and physical inactivity may increase the risk of dementia, $\mathrm{AD}$, and cognitive impairment (Qiu et al., 2007). Depression has been reported to be both a prodrome and a risk factor for dementia and $\mathrm{AD}$, and midlife rheumatoid arthritis has been reported to increase the risk for cognitive impairment later in life (Enache et al., 2011; Wallin et al., 2012). There is evidence that risk factors occurring in midlife do not always correspond to risk factors in very old age, e.g. high blood pressure in midlife is a risk factor for dementia, while the evidence in old age is inconclusive, but points rather to associations between low blood pressure and dementia and cognitive decline (Qiu et al., 2007; Molander et al., 2010a; Rastas et al., 2010). Generally, knowledge about risk factors in the very old population ( $\geq 85$ years) is limited and more research is needed.

The aim of this study is to describe factors crosssectionally associated with dementia, and identify 
factors associated with the risk of incident dementia during a five-year period of follow-up in a very old population ( $\geq 85$ years).

\section{Methods}

\section{Design and assessments}

The Umeå 85+/GERDA (GErontologisk Regional DAtabas) study is a population-based cohort study initiated in 2000. The participants were aged 85, 90 , and $\geq 95$ years, living in Umeå, Dorotea, Malå, Sorsele, Storuman, and Vilhelmina, urban and rural municipalities in the northern part of Sweden. Eligible participants were drawn from the Swedish National Tax Agency population registers. Age was the only inclusion criterion, and every other 85-year-old and all 90- and $\geq 95$-year-old individuals were eligible for inclusion. Baseline data collection was carried out in 2000-2002 and followup was done in 2005-2007. Informed consent was obtained from the participants. In cases where the eligible participant was experiencing cognitive impairment, a next of kin was asked to give consent for the participant to be approached in an appropriate manner. The participant could withdraw participation at any time. The collection of data was carried out through home visits for interview and testing, revision of medical records, and/or an interview with a next of kin or caregiver. Trained investigators performed interviews and testing.

The interview included questions about the participant's life, medical history, and current health status. Blood pressure was measured after five minutes of rest. BMI was calculated based on measured weight and height. Information was obtained about the participant's drug use, both prescribed and over-the-counter (OTC) drugs. The Mini-Mental State Examination (MMSE) was used as a global cognitive measure, ranging from a maximum score of 30 and a minimum score of 0 corresponding to the highest and the lowest level of cognitive function respectively (Folstein et al., 1975). The Organic Brain Syndrome (OBS) scale 2 was used to evaluate symptoms of depression, dementia, delirium, and other psychiatric diagnoses (Jensen et al., 1993). Depressive symptoms were assessed using the 15-item Geriatric Depression Scale (GDS-15) with scores ranging from 0-15, where a higher score indicates more depressive symptoms (Sheikh and Yesavage, 1986). When the investigator was a physician, the MontgomeryÅsberg Depression Rating Scale (MADRS) was used for further evaluation of depression (Montgomery and Åsberg, 1979). Nutritional status was measured using the Mini Nutritional Assessment (MNA) scale, where scores below 17 indicate mani- fest malnutrition and scores of 17-23.5 indicate risk of malnutrition (Guigoz et al., 1994). The Barthel ADL Index, 10-item version, was used to grade independence in personal activities of daily living (ADL), where score of 20 indicates independence and 0 indicates total dependence (Mahoney and Barthel, 1965). Psychological well-being or morale was measured using the Philadelphia Geriatric Center Moral (PGCM) scale (Lawton, 1975).

An experienced specialist in geriatric medicine carefully reviewed all the collected material and completed final diagnoses using the same criteria for all participants. Diagnoses of dementia were based on total evaluation considering available information of former dementia diagnoses according to medical records, cognitive screening (MMSE and OBS), and information obtained from interviews with the participant and/or caregiver. Diagnoses for depression were established after total evaluation of available information, reviews of former diagnoses in medical records, ongoing treatment with antidepressants, and screening with GDS-15, MADRS, OBS, and PGCM. Dementia and depression were diagnosed in line with the Diagnostic and Statistical Manual of Mental Disorders, version IV (DMS-IV) criteria (American Psychiatric Association, 1994). The collection of data in 2005-2007 was carried out in the same way as the baseline data collection. Both the sample and the method have been described in greater detail elsewhere (Von Heideken Wågert et al., 2006).

In the present study social contact was considered as the number of visits per week, both having visitors or visiting someone. Variables for education, Barthel ADL Index scores and physical activity were dichotomized. Level of education was considered low if it lasted $\leq 6$ years and high if it lasted $>6$ years, based on the fact that six years in elementary school was the general education level in this part of Sweden when participants were young. The dichotomization was done to minimize the loss due to missing data on years of schooling; however, it was possible to identify $\leq 6$ years or $>6$ years. On the Barthel ADL Index, with a range of $0-20$, scores $\geq 19$ were considered as showing independence, while scores $<19$ were considered as showing a higher degree of dependence. The participants were considered to be physically active if they had been outdoors without any help for once a month to more than four times a week, and not active if they had been outdoors without help from others more seldom or never.

\section{Sample description}

In 2000-2002, a total of 527 individuals were eligible for participation (Figure 1). Forty-four died before contact could be made and 130 declined 


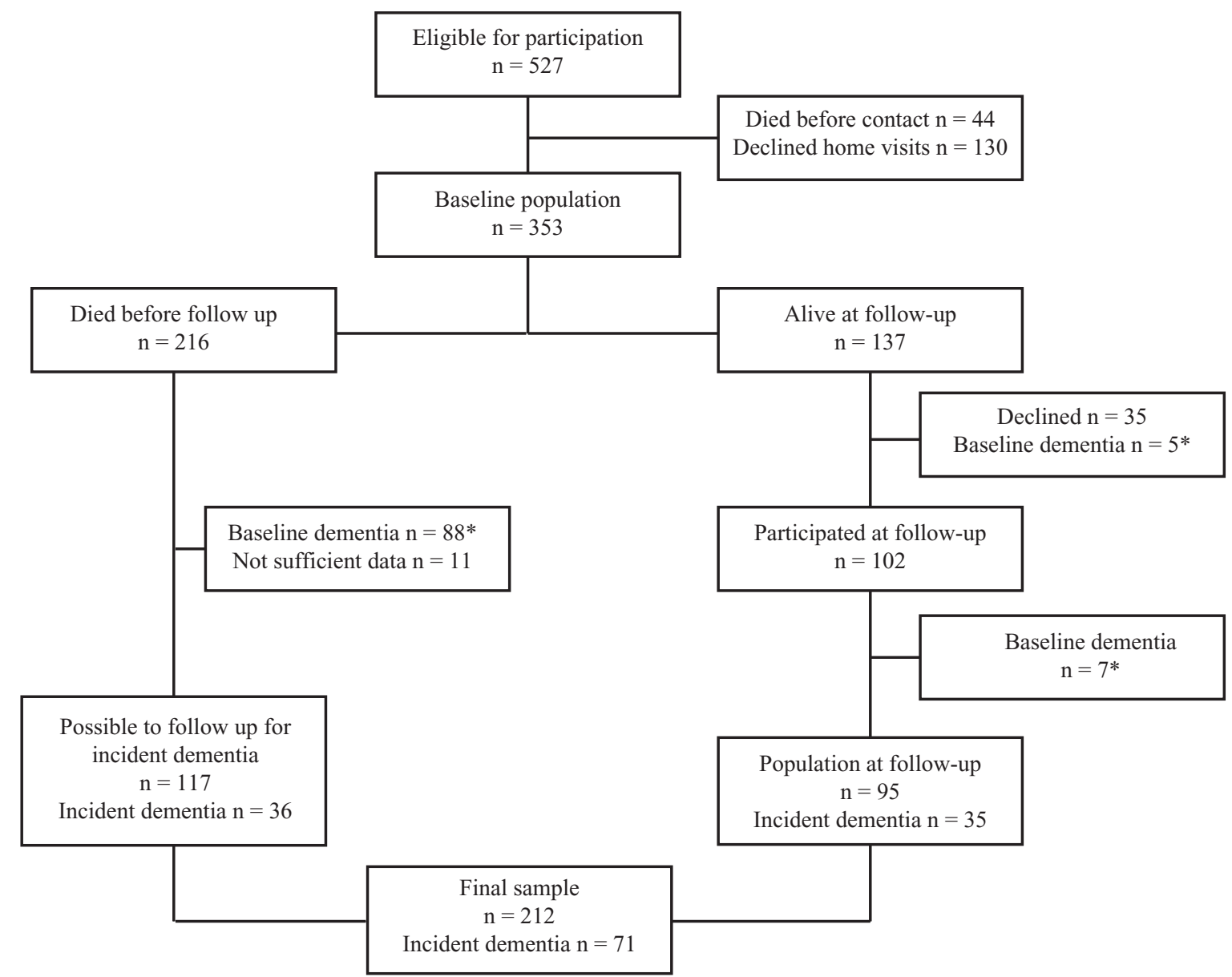

Figure 1. Study population. * Of participants at baseline who died before follow-up, $88(40.7 \%)$ had a diagnosis of dementia. Of the group alive at follow-up, only $12(8.8 \%)$ had a dementia diagnosis at baseline.

home visits. Out of the 130 individuals who declined, 78 accepted a review of their medical records and an interview with a caregiver/next of kin. These, however, are not included in the present study. The baseline population consisted of 353 participants, and did not differ regarding age and sex from the non-participants. Before follow-up, 216 baseline participants died. At follow-up, 137 participants were available but 35 declined participation, leaving 102 who participated at follow-up. These participants did not differ from the non-participants, who declined or died before follow-up $(\mathrm{n}=35+216)$, regarding the baseline characteristics of sex, education, and frequency of social contact; however, they were significantly younger ( $p<0.001$ ), scored higher on MMSE $(p<0.001)$, were more independent according to the Barthel ADL Index (dichotomized; $p<0.001$ ), and had less current depression $(\mathrm{p}=0.006)$ at baseline. As this study concerned incident dementia, participants with baseline dementia were excluded $(\mathrm{n}=7)$. Only 95 participants were left at follow-up.

It was possible to find data on incident dementia for 117 of the 216 participants who died before follow-up, since 88 out of the original 216 had baseline dementia and 11 did not have sufficient data. Death certificates were collected for all those who died before follow-up. In the group of 117 individuals, 16 incident dementia diagnoses were established from death certificates that were verified by scrutinizing medical records. The remaining 20 incident dementia cases were set after scrutinizing medical records to determine cognitive status prior to death. Neither diagnoses of dementia were set within six months from the baseline evaluation nor terminal cognitive decline two months before death was considered for dementia diagnosis. If there were uncertainties concerning the cognitive status, a specialist in geriatric medicine determined whether or not the participant met the criteria for dementia diagnosis, and if uncertainties still remained those cases were excluded.

The total number of participants at baseline who could be followed up for incident dementia was 212. This final sample did not differ from the sample eligible for participation regarding sex, but was significantly younger $(p=0.003)$. The Umeå $85+/$ GERDA study was approved by the Regional 
Table 1. Baseline socio-demographic and clinical characteristics of participants with and without dementia at baseline and those possible to be followed up for incident dementia

\begin{tabular}{|c|c|c|c|c|c|c|}
\hline & \multicolumn{3}{|c|}{$\begin{array}{l}\text { BASELINE POPULATION 2000-2002 } \\
(\mathrm{N}=353)\end{array}$} & \multicolumn{3}{|c|}{$\begin{array}{c}\text { SAMPLE FOLLOWED UP FOR } \\
\text { INCIDENT DEMENTIA }(\mathrm{N}=212)\end{array}$} \\
\hline & $\begin{array}{l}\text { DEMENTIA } \\
\mathrm{n}=100\end{array}$ & $\begin{array}{l}\text { NO } \\
\text { DEMENTIA } \\
\mathrm{n}=253\end{array}$ & $\mathrm{p}$ & $\begin{array}{l}\text { INC } \\
\text { DEMENTIA } \\
\mathrm{n}=71\end{array}$ & $\begin{array}{l}\text { INC NO } \\
\text { DEMENTIA } \\
\mathrm{n}=141\end{array}$ & $\mathrm{p}$ \\
\hline Mean age (years) & $91.18(5.02)$ & $88.89(4.19)$ & $<0.001$ & $88.54(3.70)$ & $88.92(4.35)$ & 0.522 \\
\hline Female gender* & $80(80)$ & $170(67.2)$ & 0.017 & $51(71.8)$ & $92(65.2)$ & 0.334 \\
\hline Follow-up time (years) & $\mathrm{x}$ & $\mathrm{x}$ & $\mathrm{x}$ & $3.82(1.22)$ & $3.24(1.71)$ & 0.005 \\
\hline Education $>6$ years* & $53(54.1)$ & $103(40.9)$ & 0.026 & $28(40.0)$ & $55(39.0)$ & 0.889 \\
\hline Living in an institution* & $74(74.0)$ & $69(27.3)$ & $<0.001$ & $21(29.6)$ & $35(24.8)$ & 0.459 \\
\hline Body mass index (BMI, kg/m²) & $23.10(4.88)$ & $25.32(4.42)$ & $<0.001$ & $25.28(4.91)$ & $25.26(4.22)$ & 0.984 \\
\hline Systolic blood pressure (mmHg) & $139.90(22.37)$ & $151.66(23.86)$ & $<0.001$ & $149.22(24.75)$ & $150.79(22.96)$ & 0.651 \\
\hline Diastolic blood pressure $(\mathrm{mmHg})$ & $73.66(11.75)$ & $76.30(10.65)$ & 0.048 & $75.32(10.72)$ & $76.41(10.52)$ & 0.486 \\
\hline $\begin{array}{l}\text { Mini Nutritional Assessment (MNA) } \\
\text { score }\end{array}$ & $18.82(5.43)$ & $24.66(3.45)$ & $<0.001$ & $23.76(3.45)$ & $25.06(3.43)$ & 0.011 \\
\hline $\begin{array}{l}\text { Mini-Mental State Examination } \\
\text { (MMSE) score }\end{array}$ & $11.52(7.45)$ & $25.59(3.29)$ & $<0.001$ & $24.49(3.37)$ & $26.24(2.96)$ & $<0.001$ \\
\hline $\begin{array}{l}\text { Dependence in ADL, <19 Barthel } \\
\text { score* }\end{array}$ & $82(82.0)$ & $66(26.2)$ & $<0.001$ & $23(32.9)$ & $29(20.6)$ & 0.051 \\
\hline Physically active, $>$ once per month* & $25(25.3)$ & $185(73.4)$ & $<0.001$ & $49(70.0)$ & $111(78.7)$ & 0.163 \\
\hline Social contact (number of visits) & $3.41(4.85)$ & $4.14(3.65)$ & 0.216 & $3.28(3.14)$ & $4.74(3.92)$ & 0.005 \\
\hline History of diabetes* & $15(15)$ & $30(11.9)$ & 0.425 & $12(16.9)$ & $13(9.2)$ & 0.102 \\
\hline Current depression* & $38(40)$ & $58(23.2)$ & 0.002 & $26(37.1)$ & $24(17)$ & 0.001 \\
\hline History of rheumatoid disorder* & $15(15.0)$ & $36(14.2)$ & 0.853 & $7(9.9)$ & $23(16.3)$ & 0.203 \\
\hline History of osteoarthritis* & $28(28.0)$ & $92(36.4)$ & 0.135 & $21(29.6)$ & $57(40.4)$ & 0.122 \\
\hline $\begin{array}{l}\text { Urinary tract infection in previous } \\
\text { year* }\end{array}$ & $45(45.0)$ & $54(21.3)$ & $<0.001$ & $11(15.5)$ & $33(23.4)$ & 0.180 \\
\hline Heart disease of any kind* & $61(61.0)$ & $147(58.1)$ & 0.618 & $43(60.6)$ & $80(56.7)$ & 0.594 \\
\hline History of heart failure* & $32(32.3)$ & $56(22.1)$ & 0.047 & $17(23.9)$ & $29(20.6)$ & 0.574 \\
\hline History of artrial fibrillation* & $23(23.0)$ & $41(16.2)$ & 0.135 & $9(12.7)$ & $27(19.1)$ & 0.236 \\
\hline History of stroke* & $24(24.0)$ & $47(18.6)$ & 0.252 & $13(18.3)$ & $27(19.1)$ & 0.883 \\
\hline History of TIA** & $16(16)$ & $17(6.7)$ & 0.007 & $5(7.0)$ & $9(6.4)$ & 1.000 \\
\hline \multicolumn{7}{|l|}{ Pharmaceuticals* } \\
\hline Anti-depressants & $24(24.2)$ & $34(13.5)$ & 0.015 & $12(17.1)$ & $17(12.1)$ & 0.322 \\
\hline NSAID & $8(8.1)$ & $26(10.4)$ & 0.517 & $4(5.7)$ & $16(11.4)$ & 0.184 \\
\hline ASA & $37(37.4)$ & $112(44.6)$ & 0.217 & $35(50.0)$ & $63(45.0)$ & 0.494 \\
\hline Paracetamol & $62(62.6)$ & $87(34.7)$ & $<0.001$ & $26(37.1)$ & $44(31.4)$ & 0.408 \\
\hline Oral corticosteroids** & $6(6.1)$ & $12(4.8)$ & 0.625 & $4(5.7)$ & $6(4.3)$ & 0.734 \\
\hline Beta-blockers & $11(11.1)$ & $67(26.7)$ & 0.002 & $20(28.6)$ & $39(27.9)$ & 0.914 \\
\hline ACE-inhibitors & $14(14.1)$ & $24(9.6)$ & 0.215 & $11(15.7)$ & $11(7.9)$ & 0.080 \\
\hline Bensodiazepines & $33(33.3)$ & $71(28.3)$ & 0.352 & $19(27.1)$ & $43(30.7)$ & 0.593 \\
\hline Neuroleptics & $32(32.3)$ & $22(8.8)$ & $<0.001$ & $7(10.0)$ & $10(7.1)$ & 0.474 \\
\hline
\end{tabular}

p-values represent differences between groups with and without dementia at baseline and with and without incident dementia during follow-up. Student's t-test, $\chi^{2}$, and Fisher's exact test were used when appropriate. Some variables have missing values.

Values are means (SD).

*Values are numbers (valid percentage) and $\chi^{2}$ was used.

**Values are numbers (valid percentage) and Fisher's exact test was used.

Ethical Review Board in Umeå (\$99-326, \05063M).

\section{Statistical analyses}

SPSS software for Windows, version 20.0 (SPSS Inc., IBM), was used for statistical analyses. Differences between groups with and without dementia at baseline, and with and without incident dementia, were analyzed using Student's T-test, $\chi^{2}$, and Fisher's exact test when appropriate. Taking into account baseline variables associated with incident dementia $(n=212)$, with a p-value less than 0.150 (Table 1), the final multivariate logistic regression model was established using standard statistical modeling. Several additional models were 
Table 2. Baseline factors associated with incident dementia, divided into age groups

\begin{tabular}{|c|c|c|c|c|}
\hline & $\begin{array}{l}85 \text { YEARS } \\
N=96\end{array}$ & $\begin{array}{l}90 \text { YEARS } \\
\mathrm{N}=81\end{array}$ & $\begin{array}{l}\geq 95 \text { YEARS } \\
\mathrm{N}=35\end{array}$ & $\mathrm{p}$ \\
\hline Incident dementia* & $31(32.3)$ & $32(39.5)$ & $8(22.9)$ & $\begin{array}{l}\mathrm{p}^{(85-90)}=0.318 \\
\mathrm{p}^{(90-95)}=0.083 \\
\mathrm{p}^{(85-\geq 95)}=0.296\end{array}$ \\
\hline Follow-up (years) & 3.76 & 3.33 & 2.79 & $\begin{array}{l}\mathrm{p}^{(85-90)}=0.073 \\
\mathrm{p}^{(90-95)}=0.106 \\
\mathrm{p}^{(85-\geq 95)}=\mathbf{0 . 0 0 1}\end{array}$ \\
\hline MMSE score & $26.60(2.68)$ & $24.81(3.47)$ & $24.94(3.29)$ & $\begin{array}{l}\mathrm{p}^{(85-90)}<\mathbf{0 . 0 0 1} \\
\mathrm{p}^{(90-95)}=0.864 \\
\mathrm{p}^{(85-\geq 95)}=\mathbf{0 . 0 1 3}\end{array}$ \\
\hline Social contact, number of visits & $4.20(3.54)$ & $4.29(3.63)$ & $4.38(4.65)$ & $\begin{array}{l}\mathrm{p}^{(85-90)}=0.874 \\
\mathrm{p}^{(90-95)}=0.913 \\
\mathrm{p}^{(85-\geq 95)}=0.825\end{array}$ \\
\hline Current depression* & $21(21.9)$ & $22(27.2)$ & $7(20.6)$ & $\begin{array}{l}\mathrm{p}^{(85-90)}=0.414 \\
\mathrm{p}^{(90-95)}=0.459 \\
\mathrm{p}^{(85-\geq 95)}=0.875\end{array}$ \\
\hline
\end{tabular}

Values are means (SD).

*Values are numbers (valid percentage) and $\chi^{2}$ was used.

tested to confirm the results by adding all variables associated with baseline dementia, in the baseline population of 353 participants, with a p-value of less than 0.150 (Table 1), and according to relevance as presented in the literature. However, no additional variables met significance, or changed the results, and were therefore not included in the final model.

The longitudinal analysis is based on the sample of 212 participants. However, due to missing values in the social contact variable $(n=15)$, the analysis includes 197 participants. Sixty-five of these participants were having incident dementia. The results are considered significant for $\mathrm{p}<0.05$.

\section{Results}

\section{Socio-demographic and clinical characteristics}

Socio-demographic and clinical characteristics are presented in Table 1 . In the total population of 353 participants at baseline, the mean age (SD) was $89.54(4.55)$ years, and $250(70.8 \%)$ were women. Socio-demographic and clinical characteristics at baseline are also shown in Table 1 for the sample followed up for incident dementia $(n=212)$.

\section{Prevalence, incidence, and prognosis of dementia}

The prevalence of dementia in the baseline population was $28.0 \%$. There was a significant difference between the age groups, 85 and
90 to $95+$ years, but not between 85 and 90 years, with a prevalence of $20.6 \%, 24.6 \%$, and $47.6 \%$ respectively. During five years, 71 of the $212(33.5 \%)$ participants developed dementia (Figure 1). Incident dementia during the followup time was $32.3 \%, 39.5 \%$, and $22.9 \%$ for the respective age groups (Table 2 ). Significantly, more women than men had dementia $(\mathrm{p}=0.017)$ and depression $(p=0.027)$ at baseline. No difference was seen in incident dementia between women and men. Among participants with a diagnosis of dementia at baseline, $12 \%$ were still alive at the five-year follow-up compared with $54.1 \%(<0.001)$ among participants without dementia (Figure 1).

\section{Cross-sectional association with dementia at baseline}

The participants with dementia diagnoses at baseline were significantly older than those without dementia (Table 1). They also had significantly lower diastolic (DBP) and systolic blood pressure (SBP), lower BMI, and a higher proportion had a history of heart failure and transient ischemic attack (TIA). In addition, significantly more of the participants with dementia had current depression, and had had a urinary tract infection within the year before the interview. They also scored lower on MNA and MMSE scales and a larger proportion was dependent on ADL and had a lower physical activity level. There was a more frequent use of antidepressants, paracetamol, and neuroleptics in participants with dementia. Participants without 
Table 3. Baseline variables associated with incident dementia

\begin{tabular}{|c|c|c|c|}
\hline & $\begin{array}{l}\text { OR }(95 \% \text { CI }) \\
\text { FOR INCIDENT } \\
\text { DEMENTIA }\end{array}$ & $\mathrm{p}$ & WALD \\
\hline Follow-up time & $1.61(1.26-2.05)$ & $<0.001$ & 14.30 \\
\hline MMSE score & $0.83(0.74-0.93)$ & 0.001 & 10.48 \\
\hline Baseline depression & $2.91(1.37-6.16)$ & 0.005 & 7.75 \\
\hline Social contact & $0.87(0.78-0.97)$ & 0.009 & 6.77 \\
\hline
\end{tabular}

Values are odds ratios $(95 \% \mathrm{CI})$ from multivariate logistic regression in this longitudinal model with incident dementia as a dependent variable.

Nagelkerke $\mathrm{R}^{2}=0.262$.

dementia had a significantly lower level of education and used more beta-blockers.

\section{Longitudinal associations with dementia over five years}

In a multivariate logistic regression analysis, depression at baseline and follow-up time were associated with a higher risk of incident dementia, odds ratio (OR) (95\% CI, p-value) was 2.91 $(1.37-6.16,0.005)$ and $1.61(1.26-2.05,<0.001)$ respectively (Table 3 ). More social contact at baseline was associated with a lower risk of incident dementia, OR (95\% CI, p-value) was 0.87 (0.78$0.97,0.009)$, as was a higher score on MMSE at baseline, OR (95\% CI, p-value) was 0.83 (0.74-0.93, 0.001) (Table 3). Adjusting the results for age and sex had no effect on final results. Results were also adjusted for the Barthel ADL Index (dichotomized), living alone or living in an institution, and for several cardiovascular risk factors and disorders (BMI, SBP, DBP, physical activity, and history of stroke, TIA, diabetes, heart failure, atrial fibrillation, heart disease of any kind) as well as diseases with increased inflammatory activity apart from the cardiovascular disorders (history of osteoarthritis and rheumatoid disorders) and anti-inflammatory treatment. That did not change the results (data not shown).

\section{Discussion}

In this population-based cohort study of the very old, the prevalence of dementia was $28 \%$ at baseline, and $80 \%$ of the participants with dementia were women. Only $12 \%$ of the participants with a dementia diagnosis at baseline remained alive five years later. In the population that could be followed up for incident dementia, another 71 participants $(33.5 \%)$ developed dementia over five years. Depression at baseline and follow-up time were associated with a higher risk of incident dementia, while more social contacts and higher MMSE scores at baseline were associated with a lower risk.

Both the prevalence of dementia and the high mortality among participants with dementia are in line with earlier research. The incidence of dementia in 85- and 90-year-old people is also in line with earlier research (Fratiglioni et al., 2008; Rastas et al., 2010). The percentage of incident dementia in the age group of $\geq 95$ years is lower than in the 85 - and 90 -year-old age groups but should be interpreted with caution since there were few incident dementia cases in the oldest age group and the follow-up time was shorter due to a high mortality rate in the oldest age group (Table 2).

To our knowledge this is the first study to examine the association between diagnosis of current depression and incident dementia in a population of very old people ( $\geq 85$ years), suggesting that depression is a risk factor for dementia. In a recent study, depressive symptoms (GDS-15 $\geq 6$ ) were associated with a higher risk of mild cognitive impairment (MCI) and dementia in very old women ( $\geq 85$ years) (Spira et al., 2012). Depression has been reported to reduce cognitive function, commonly occurs in subjects with MCI and dementia at frequencies covering a wide range from $6 \%$ to as high as $83 \%$, and it has been suggested as both a prodrome and a risk factor for dementia (Enache et al., 2011; Rodda et al., 2011). On the other hand, dementia has been reported to increase the risk of depression (Rodda et al., 2011).

The vascular hypothesis and the role of inflammation are the hypotheses applied to both depression and dementia. It is suggested that previous vascular events and risk factors increase the risk of depressive symptoms (Byers and Yaffe, 2011), and it is established that these increase the risk of dementia (Qiu et al., 2007; Mangialasche et al., 2012). Depression also has been associated with subsequent vascular disease (Byers and Yaffe, 2011). Increased inflammation measured with such markers as Interleukin-1 (IL-1), IL-6, tumor necrosis factor (TNF), and C-reactive protein (CRP) in serum or plasma have been associated with both depression and cognitive decline, $\mathrm{AD}$, and dementia, although the results are not consistent (Dziedzic, 2006; Christmas et al., 2011). Presence of inflammation has been reported in the cascade leading to neuropathological changes typical of dementia, and inflammation could be a cause of, contributing factor to, or result of the development of dementia and $\mathrm{AD}$ (Dziedzic, 2006). Based on our results, it is not possible to disentangle the role of vascular disorders/hypothesis and inflammation in relation to depression and dementia. The 
final model was controlled for cardiovascular and cerebrovascular risk factors and diseases as well as diseases with increased inflammatory activity and use of anti-inflammatory drugs, but this did not alter the results.

Another possible link between depression and dementia is the reported change in the hypothalamic-pituitary-adrenal (HPA) axis during depression, more frequently occurring in late-life depression. HPA dysregulation could eventually, by affecting levels of glucocorticoids, lead to hippocampal atrophy and hence suggests that depression is a risk factor for dementia, and $\mathrm{AD}$ in particular. However, hippocampal atrophy due to $\mathrm{AD}$ could also generate depressive symptoms, suggesting depression is a prodrome of $\mathrm{AD}$ (Butters et al., 2008)

The diagnosis of MCI, a higher level of cognitive decline than normal but one that does not fulfill the criteria for dementia (Petersen, 2004), was not considered in Umeå 85+/GERDA. Based on the baseline measure of MMSE, we can assume that participants with MCI are present in our material. The coexistence of MCI, dementia, and depression diagnoses makes it difficult to determine the causal relationship. In the study population of 353 participants, those with baseline depression scored significantly lower on MMSE, even when participants with a diagnosis of dementia were removed (data not shown). The same was true for the group followed up for incident dementia. MCI as a diagnosis in the continuum toward dementia has been controversial, since subjects with MCI have been shown to proceed toward dementia, remain in the MCI group, or even in some cases to move toward normal cognition (Mitchell and Shiri-Feshki, 2009). However, dementia is a clinical diagnosis and the participants with incident dementia during the follow-up period did not meet the criteria for dementia at baseline.

The finding that more frequent social contact is associated with a lower risk of dementia is in line with the psychosocial hypothesis as part of the reserve hypothesis, which implies that mental and physical stimuli during the lifetime will allow the brain to endure more damage before developing clinical signs (Fratiglioni and Wang, 2007; Qiu et al., 2007). The results support the findings of previous research that social networks, assessed through various measures from quantity and/or quality of contacts to indices of social activity or social ties, reduce the risk of cognitive decline and dementia (Fratiglioni et al., 2004). Social networks have been shown to modify the relation between $\mathrm{AD}$ pathology and cognitive function (Bennett et al., 2006). In order to clarify the effect of number of visits, the perception of the visit was not taken into consideration, since this might be influenced by a current depression. Considering that, for example, social contacts (number of visits) might be influenced by various aspects related to independence and living conditions, the analyses were adjusted for the Barthel ADL Index (dichotomized) and living alone or living in an institution. Doing this did not change the results.

When considering the risk factors, derived from the literature, known to increase risk from midlife to late-life, few emerged as significant for the group that could be followed up for incident dementia or in the longitudinal models and were therefore not included in the final model. This was somewhat surprising, especially considering the numerous vascular and inflammatory factors. In the baseline group of 353 participants, e.g. low BMI, SBP, DBP, history of heart failure, and TIA were associated with dementia. The associations of SBP and DBP in the Umea $85+/$ GERDA population have been investigated more thoroughly elsewhere, suggesting that the decrease in SBP over time is associated with incident dementia (Molander et al., 2010b). In some cases the lack of significance, in some vascular and inflammatory factors, could be due to a power issue (e.g. history of TIA). Surprisingly, the level of education was significantly lower in the group without dementia at baseline. However, when education was considered as a continuous variable, this significance was lost and no difference was seen between the groups with and without dementia. It seems as if the association of education with dementia risk is not as important in this group of the very old.

\section{Implications for intervention}

The results of this study are important from several aspects. First, it is certainly necessary to study risk factors for dementia in the very old age group as they are part of the segment of the population that is increasing the most. Second, dementia comes with high mortality in these age groups and establishing risk factors could ultimately lead to prevention or treatment options. Third, irrespective of the discussion about whether depression is an early sign of, or a risk factor for, dementia, it should be considered that observation of signs of depression in the very old people may lead to early detection of the development of dementia and appropriate treatment for the patient. In this study the population was too small to allow consideration of whether the treatment of depression was altering the risk regarding responders and non-responders to antidepressants. Fourth, the frequency of social contacts seems to be important in the very old age 
group and might be a future target in intervention studies. Finally, it is intriguing to hypothesize that cardiovascular risk factors, inflammation, and the brain reserve model might have different roles in the very old as opposed to the younger old as part of the life-course perspective. Considering that the population surviving to this age, despite possible risk factors earlier in life, is a rather select group, the risk factors profile could differ from the profiles seen in mid- to late-life.

\section{Strengths and limitations of the study}

This study has several strengths. It is a populationbased cohort study considering the very old age group ( $\geq 85$ years), a group not often studied, with a longitudinal design and a five-year followup, also unusual for this age group. Age was the only inclusion criterion, hence the population is unselected, including people living at home and in institutional care. Apart from the factors considered for the final model, more factors from the extensive Umeå 85+/GERDA material were considered and tested but without influencing the result (data not shown); however, even though great caution was taken, we cannot totally exclude the possibility of residual confounding. The acquisition of information about incident dementia in the group who died during the follow-up period is a strength of the present study since such information is not normally considered in the literature. All diagnoses in the Umeå 85+/GERDA material were reviewed by a specialist in geriatric medicine.

One limitation is the high dropout rate, and thus the relatively small population, although this is to be expected when studying the very old age group. We have, to some degree, minimized this limitation by acquiring information about those who died. These results are applicable to the very old population of 85,90 , and $\geq 95$-year-old individuals and should not be applied generally. Diagnoses were established after reviewing all the material, and the specialist in geriatric medicine did not see the participants (except those assessed by him). The diagnoses in participants who died before the five-year follow-up were established based on death certificates and medical records. These are limitations; however, great caution was taken and if there was any uncertainty, a subject was not included in the analysis.

\section{Conclusions}

There is a high prevalence and incidence of dementia among very old people. Depression is associated with a higher risk of incident dementia among very old people over a period of five years, whereas more frequent social contacts and higher MMSE scores are associated with a lower risk. More research is needed about risk and protective factors in the very old age group, yet depression and social contacts are the factors that might be suitable targets in future intervention studies.

\section{Conflict of interest}

M. Kivipelto received honoraria for serving on the scientific advisory board of Elan and Pfizer, and has served as a speaker on scientific meetings organized by Janssen, Novartis, Pfizer, Elan, and Merz.

\section{Description of authors' roles}

Y. Gustafson designed the GERDA study, supervised the data collection, collected data, and assisted in statistical analyzing and writing of the paper. K. Wallin assisted in collecting the data, analyzed the data, and wrote the paper. G. Boström collected data and assisted in writing the paper. $M$. Kivipelto assisted in analyzing the statistics and writing the paper.

\section{Acknowledgments}

The authors thank all Umeå $85+/$ GERDA participants and members of the Umeå $85+/$ GERDA study group for their cooperation, data collection, and management. The GERDA-project was supported by grants from the European Union Bothnia-Atlantica Program, the Vårdal Research Foundation, the King Gustav V and Queen Victoria Foundation of Freemasons, the Umea University Foundation for Medical Research, the Erik and Anne-Marie Detlof Foundation, the Swedish Dementia Association, Interreg IIIA MittSkandia Program, the Alzheimer Foundation, the Swedish Research Council (K2005-27VX-15357$01 \mathrm{~A})$, the regional agreement between Umeå University and Västerbotten County Council (ALF), and Stiftelsen Dementia.

\section{References}

American Psychiatric Association. (1994). Diagnostic and Statistical Manual of Mental Disorders, 4th edn. Washington, DC: American Psychiatric Association.

Bennett, D. A., Schneider, J. A., Tang, Y., Arnold, S. E. and Wilson, R. S. (2006). The effect of social networks on the relation between Alzheimer's disease pathology and level of cognitive function in old people: a longitudinal study. Lancet Neurology, 5, 406-412. 
Butters, M. A. et al. (2008). Pathways linking late-life depression to persistent cognitive impairment and dementia. Dialogues in Clinical Neuroscience, 10, 345357.

Byers, A. L. and Yaffe, K. (2011). Depression and risk of developing dementia. Nature Reviews. Neurology, 7, 323-331.

Christmas, D. M., Potokar, J. and Davies, S. J. (2011). A biological pathway linking inflammation and depression: activation of indoleamina 2,3-dioxygenase. Neuropsychiatric Disease and Treatment, 7, 431-439.

Dziedzic, T. (2006). Systemic inflammatory markers and risk of dementia. American fournal of Alzheimer's Disease and other Dementias, 21, 258-262.

Enache, D., Winblad, B. and Aarsland, D. (2011). Depression in dementia: epidemiology, mechanisms, and treatment. Current Opinion in Psychiatry, 24, 461-472.

Folstein, M. F., Folstein, S. E. and McHugh, P. R. (1975). "Mini-Mental State": a practical method for grading the cognitive state of patients for the clinician. Fournal of Psychiatric Research, 12, 189-198.

Fratiglioni, L., Paillard-Borg, S. and Winblad, B. (2004). An active and socially integrated lifestyle in late life might protect against dementia. Lancet Neurology, 3, 343-353.

Fratiglioni, L., von Strauss, E. and Qiu, C. (2008). Epidemiology of the dementias of old age. In R. Jacoby, C. Oppenheimer, T. Dening and A. Thomas (eds.), Oxford Textbook of Old Age Psychiatry (pp. 391-506). Oxford, UK: Oxford University Press.

Fratiglioni, L. and Wang, H. X. (2007). Brain reserve hypothesis in dementia. Fournal of Alzheimer's Disease, 12, 11-22.

Guigoz, Y., Vellas, B. and Garry, P. J. (1994). Mini-Nutritional Assessment: a practical assessment tool for grading the nutritional state of elderly patients. Facts, Research and Intervention in Geriatrics, 4, 15-59.

Jensen, E., Dehlin, O. and Gustafson, L. (1993). A comparison between three psychogeriatric rating scales. International fournal of Geriatric Psychiatry, 8, 215-229.

Lawton, M. P. (1975). The Philadelphia Geriatric Center Morale Scale: a revision. Fournal of Gerontology, 30, 8589.

Mahoney, F. I. and Barthel, D. W. (1965). Functional evaluation: the Barthel Index. Maryland State Medical fournal, 14, 61-65.

Mangialasche, F., Kivipelto, M., Solomon, A. and Fratiglioni, L. (2012). Dementia prevention: current epidemiological evidence and future perspective. Alzheimer's Research and Therapy, 4, 6.
Mathillas, J., Lövheim, H. and Gustafson, Y. (2011). Increasing prevalence of dementia among very old people. Age and Aging, 40, 243-249.

Mitchell, A. J. and Shiri-Feshki, M. (2009). Rate of progression of mild cognitive impairment to dementia meta-analysis of 41 robust inception cohort studies. Acta Psychiatrica Scandinavica, 119, 252-265.

Molander, L., Gustafson, Y. and Lövheim, H. (2010a). Low blood pressure is associated with cognitive impairment in very old people. Dementia and Geriatric Cognitive Disorders, 29, 335-341.

Molander, L., Gustafson, Y. and Lövheim, H. (2010b). Longitudinal associations between blood pressure and dementia in the very old. Dementia and Geriatric Cognitive Disorders, 30, 269-276.

Montgomery, S. A. and Åsberg, M. (1979). A new depression scale designed to be sensitive to change. The British Fournal of Psychiatry, 40, 382-389.

Petersen, R. C. (2004). Mild cognitive impairment as a diagnostic entity. Fournal of Internal Medicine, 256, 183-194.

Qiu, C., De Ronchi, D. and Fratiglioni, L. (2007). The epidemiology of the dementias: an update. Current Opinion in Psychiatry, 20, 380-385.

Rastas, S. et al. (2010). Vascular risk factors and dementia in the general population aged $>85$ years: prospective population-based study. Neurobiology of Aging, 31, 1-7.

Rodda, J., Walker, Z. and Carter, J. (2011). Depression in older adults. BMF, 343, d5219.

Sheikh, J. I. and Yesavage, J. A. (1986). Geriatric Depression Scale (GDS): recent evidence and development of a shorter version. Clinical Gerontologist, 5, 165-172.

Spira, A. P., Rebok, G. W., Stone, K. L., Kramer, J. H. and Yaffe, K. (2012). Depressive symptoms in oldest-old women: risk of mild cognitive impairment and dementia. The American fournal of Geriatric Psychiatry, 20, 1006-1015. doi:10.1097/JGP.0b013e318235b611.

United Nations, Population Division. (2010). World Population Prospects, the 2010 Revision (database on the Internet). Available at: http://esa.un.org/wpp/ Documentation/pdf/WPP2010_Highlights.pdf; last accessed 31 May 2012.

von Heideken Wågert, P. et al. (2006). Health status in the oldest old. Age and sex differences in the Umea 85+study. Aging Clinical and Experimental Research, 18, 116-126.

Wallin, K., Solomon, A., Kåreholt, I., Tuomilehto, J., Soininen, H. and Kivipelto, M. (2012). Midlife rheumatoid arthritis increases the risk of cognitive impairment two decades later: a population-based study. Fournal of Alzheimer's Disease, 31, 669-676. 